\title{
Delay Analysis in EPC Projects using Ishikawa Diagram
}

Alaa Khalfan Al Ghaithi ${ }^{1}$, Rafeeq Ameen Kattiparuthi ${ }^{2}$, Alaa Moosa Koya ${ }^{3}$

\author{
${ }^{1}$ B Sc, Built and Natural Environment Department, Caledonian College of Engineering, Glasgow Caledonian University \\ Muscat Sultanate of Oman, \\ ${ }^{2}$ Faculty Built and Natural Environment Department, Caledonian College of Engineering, Glasgow Caledonian University \\ Muscat Sultanate of Oman, \\ ${ }^{3} \mathbf{M}$ Tech, Traffic and Transportation Planning, National Institute of Technology, India
}

\begin{abstract}
Delay is one of the major issues in EPC projects in Oman. Project managers are not considering the root causes of delay while taking preventive measures. This project aims to identify the most common types of delay in EPC projects, to find out the root causes of delay by using Ishikawa diagram and further to prepare acceleration plan for a running project by using schedule compression techniques. The objectives of this project are: (a ) to identify root causes of various delays commonly affecting the EPC projects in Oman by using Ishikawa diagram. (b) to identify critical delay cause factors for a running project by conducting questionnaire survey. (c) to prepare acceleration plan for the project by using schedule compression techniques. To achieve this study: all the information was collected, schedules were compared to calculate the delay in each activity, questionnaire survey was conducted to study the impact of various factors causing delay and the root causes by using Ishikawa diagram and finally prepared an acceleration plan by using schedule compression techniques. The results found are: time and cost constraints are the biggest obstacle causing delay in EPC projects. The study identified the importance of analyzing the root causes before taking any particular preventive measures.
\end{abstract}

Keywords - Ishikawa diagram, Delay analysis, Crashing, Pareto chart.

\section{INTRODUCTION}

Sultanate of Oman is one of the developing economies in the Middle East in which its development depends on the construction industry as an important sector. Increase in the population in Oman is demanding the development of infrastructure. The government is spending billions of Omani rials every year in major projects in the development of the country. If a range of projects schedules are being reviewed it can be seen that in some projects the delay ranges from few days to several months to over a year in some projects. To avoid these delay factors in EPC projects it is important to analyse the delay factor. This project has tried to conduct an extensive study to find out the root causes of delay in EPC projects in Oman by using Ishikawa diagram, which is commonly used to find out the root causes of quality related problems.

The aim of this project is to identify the most common types of delay in EPC projects, to find out the root causes of delay by using Ishikawa diagram and further to prepare acceleration plan for a running project by using schedule compression techniques.

The objectives of the project are as follows:

- To identify root causes of various delays commonly affecting the EPC projects in Oman by using Ishikawa diagram.

- To identify critical delay cause factors for a running project by conducting questionnaire survey.

- To prepare acceleration plan for the project by using schedule compression techniques.

The site selected to conduct the case study is "Ras $\mathrm{Al}$ Hamra Substation". It is a project handling by STST for PDO as their client. PDO initiated a development project in RAH area to construct additional residential buildings, school, club, hotels etc. The objective of "Ras Al Hamra Substation" project is to supply power arrangement required for the RAH developments and to recommend the best techno - economic option. The baseline schedule for this project has been revised two times, which shows the scope of this research study.

Literature Review:

Aibinu and Jagboro (2002) identified and evaluated the effects of delays on building project execution in Nigeria. Construction delay has become endemic in Nigeria. It is

Page | 750 
imperative to create awareness of the extent to which delays can adversely affect project delivery. They identified, by questionnaire evaluates and through empirical method to assess the effects of construction delays. The findings showed that time and cost overruns were frequent effects of delay. Delay had significant effect on completion cost and time of 61 building projects studied. Client-related delay is significant in Nigeria. Acceleration of site activities coupled with improved clients' project management procedure and inclusion of appropriate contingency allowance in precontract estimate should assuage the adverse effect of construction delays.

Arditi and Pattanakitchamroon (2006) through their research establish selection guidelines for delay analysts by comparing the characteristics of the most commonly used delay analysis methods, and considering their advantages and disadvantages under different circumstances. The selection of the proper analysis method depends upon a variety of factors including information available, time of analysis, capabilities of the methodology and time, funds and effort allocated to the analysis. The authors reviewed 20 research studies that discuss various aspects of delay analysis methods and summarize the advantages and disadvantages of widely used delay analysis methods. They also discuss the most important issues in delay analysis that affect the results of the analysis. The selection of a suitable analysis method depends heavily on the availability of scheduling data, the familiarity of the analyst with the capabilities of the software used in the project, clear specifications in the contract concerning the treatment of concurrent delays and the ownership of float.

Yang and Kao (2009) develop a comprehensive method to help delay analysis. A review of delay analysis methods was done along with Comparison of three process-based dynamic analysis methods, namely, the snapshot analysis method, the windows analysis method and the isolated delay type method. Six suggestions on developing an ideal delay analysis method are: concerning of as-planned and asbuilt schedules, dealing with various delay types, providing clear liability distribution, considering multiple critical paths and critical path(s) change, defining total float in a clear position and incorporating the system into popular commercial scheduling software.

Nguyen and Ibbs (2006) to ensure more efficient delay analyses and claims compared the improved schedule window analysis considering resource allocation with the traditional schedule window analysis. The result obtained through the comparison of the improved window analysis with the existing window analysis is that resource allocation can affect the result of a delay analysis. Performing a schedule analysis without considering resource allocations may increase the owner's or contractor's risk of assuming delay responsibility which is not his or her fault. This research enables more reliable schedule analysis. Therefore, further research will be focused to increase the usability, credibility and acceptability of delay analysis.

Abdul-Rahman, Wang and Jackson (2011) conduct a study identify issues in implementing quality systems in design and build projects. Their aim was to focus on the project manager's point of views on the implementation of quality system in design-and-build projects especially using the Ishikawa diagram. To carry out this case study, a questionnaire survey was employed to collect data from 198 targeted project management consultant firms and construction management firms all over Malaysia to identify issues in implementing quality systems in designand-build projects.

\section{METHODOLOGY}

The project is aimed to identify the most common types of delay in EPC projects, to find out the root causes of delay by using Ishikawa diagram and further to prepare acceleration plan for a running project by using schedule compression techniques. The following are the methodology steps used to accomplish the objectives of the project:

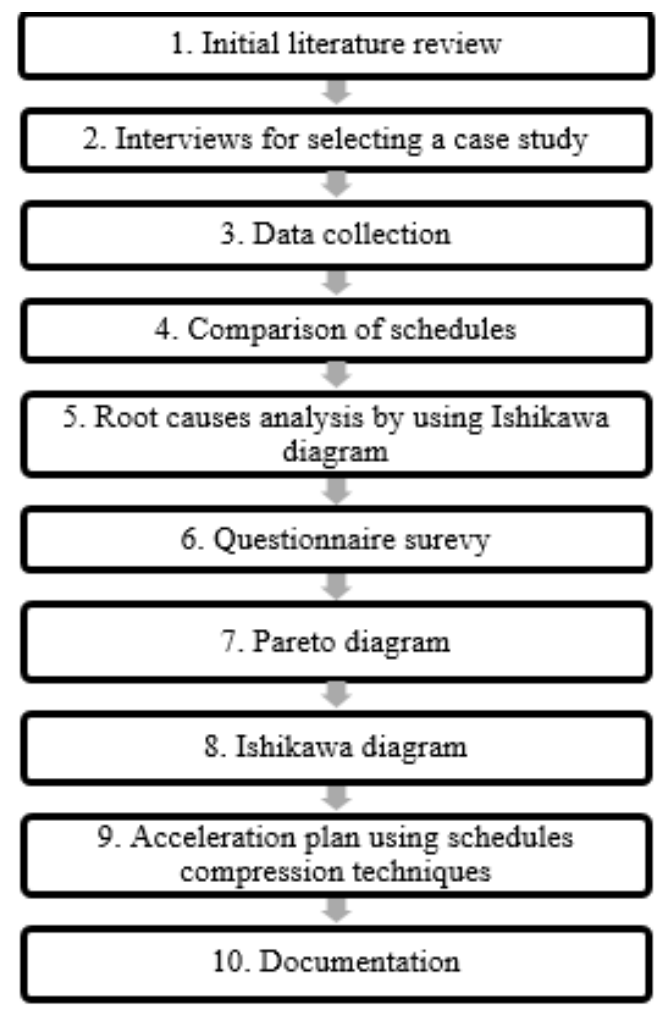

Fig.1: Flow chart exhibiting the project stages 
1. Initial literature review: several journal papers were reviewed to get general and specific idea regarding the selected topic.

2. Interviews for selecting a case study: interviews with employees of various levels for selecting a proper case study for the selected topic.

3. Data collection: discussions with the stakeholders of the selected project to collect the necessary information and data.

4. Comparison of schedules: comparison between the baseline schedule and the revised schedules to calculate the total numbers of days delayed in each activity and total duration of project.

5. Root causes analysis by using Ishikawa diagram: based on the literature research, the interviews and the collected data about the project, all the root causes of delay in the project were identified and further detailed analysis is done by Ishikawa diagram.

6. Questionnaire survey: designed and circulated among key stakeholder of the selected project to find out the relative importance index of each root cause identified through the analysis of Ishikawa diagram.

7. Pareto diagram: prepared to identify the vital root causes that are responsible for causing most of the delay in the project.

8. Ishikawa diagram: again further extensive investigation has conducted to identify the root causes of the vital delay factors identified through the questionnaire survey analysis and Pareto diagram.

9. Acceleration plan using schedule compression techniques.

10. Preparation of final report.

\section{RESULTS AND ANALYSIS}

a) From the comparison of the baseline and revised schedules, the delay in each activity was calculated to find in which activity the major delay was caused and further to calculate the total delay days in the total duration of the project. The comparison was done for around 280 activities and the total delay in engineering, procurement and construction is shown in table 1 and total delay days in the total duration of the project in table 2 .

Table.2: Total delay days in the total duration of the project

\begin{tabular}{lcc}
\hline \multicolumn{1}{c}{ Activity } & $\begin{array}{c}\text { Days delayed } \\
\text { (BL - R01) }\end{array}$ & $\begin{array}{c}\text { Days delayed } \\
\text { (R01 -R02) }\end{array}$ \\
\hline Engineering & -34 & -198 \\
Procurement & -44 & -127 \\
Construction & -55 & -101 \\
\hline
\end{tabular}

Table.1: Total delay in engineering, procurement and construction

\begin{tabular}{ccc}
\hline \multirow{2}{*}{ Total Delay } & $\begin{array}{c}\text { Days delayed } \\
(\text { BL -R01) }\end{array}$ & $\begin{array}{c}\text { Days delayed } \\
\text { (R01 -R02) }\end{array}$ \\
\cline { 2 - 3 } & -61 & -77 \\
\hline
\end{tabular}

b) Based on the literature research, the interviews and the collected data about the project, all the root causes of delay in the project were identified and further detailed analysis is done by Ishikawa diagram as shown in figure 6.

c) The questionnaire survey sample size was 20 and from it the relative importance index of each root cause identified through the analysis of Ishikawa diagram was found. The formula used to do the analysis is given below:

$$
\mathrm{RII}=\frac{(5 M 1+4 M 2+3 M 3+2 M 2+1 M 5)}{5(M 1+M 2+M 3+M 2+M 5)}
$$

The RII values ranged between $0-1$ and ranked in groups based on their effect on project delay. Table 3 shows the groups and RII ranges.

Table.3: The groups and RII ranges

\begin{tabular}{cc}
\hline RII range & Group \\
\hline $1-0.80$ & Critical \\
$0.79-0.60$ & Near critical \\
$0.59-0.40$ & Moderate \\
$0.39-0.10$ & Low \\
$0.9-0$ & Negligible \\
\hline
\end{tabular}

d) Pareto chart was used to arrange the results from the most critical to least critical factors to identify the vital delay factors as shown in figure 5 .

e) From the analysis of the questionnaire, the critical factors causing delay to the project are time and cost. Hence further interviews were conducted to find out the root causes leading to each critical factor as illustrated in figures 7 and 8.

f) An acceleration plan using PRIMAVERA 6 was prepared. The schedule compression method was used to prepare the acceleration plan. Among the crashing and fast tracking techniques of schedule compression method, the crashing technique was adopted as the fast tracking technique was already used during the preparation the two revised schedules. Although the crashing method is not the preferred technique due to the compromise in quality of the work and the peak in cost of the project. The prepared plan resulted with an acceleration of around 40 days. 


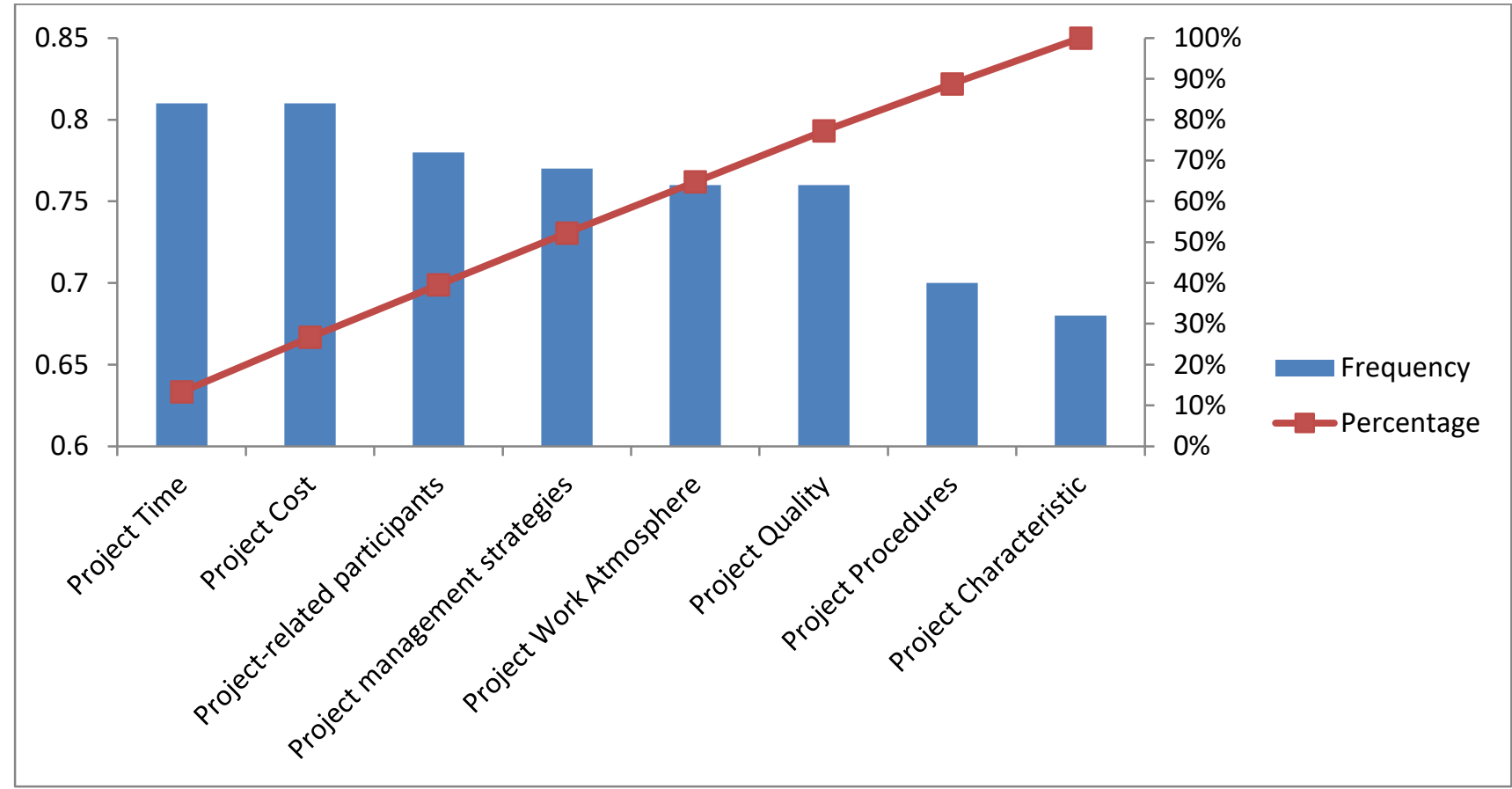

Fig.2: Pareto chart for vital delay factors

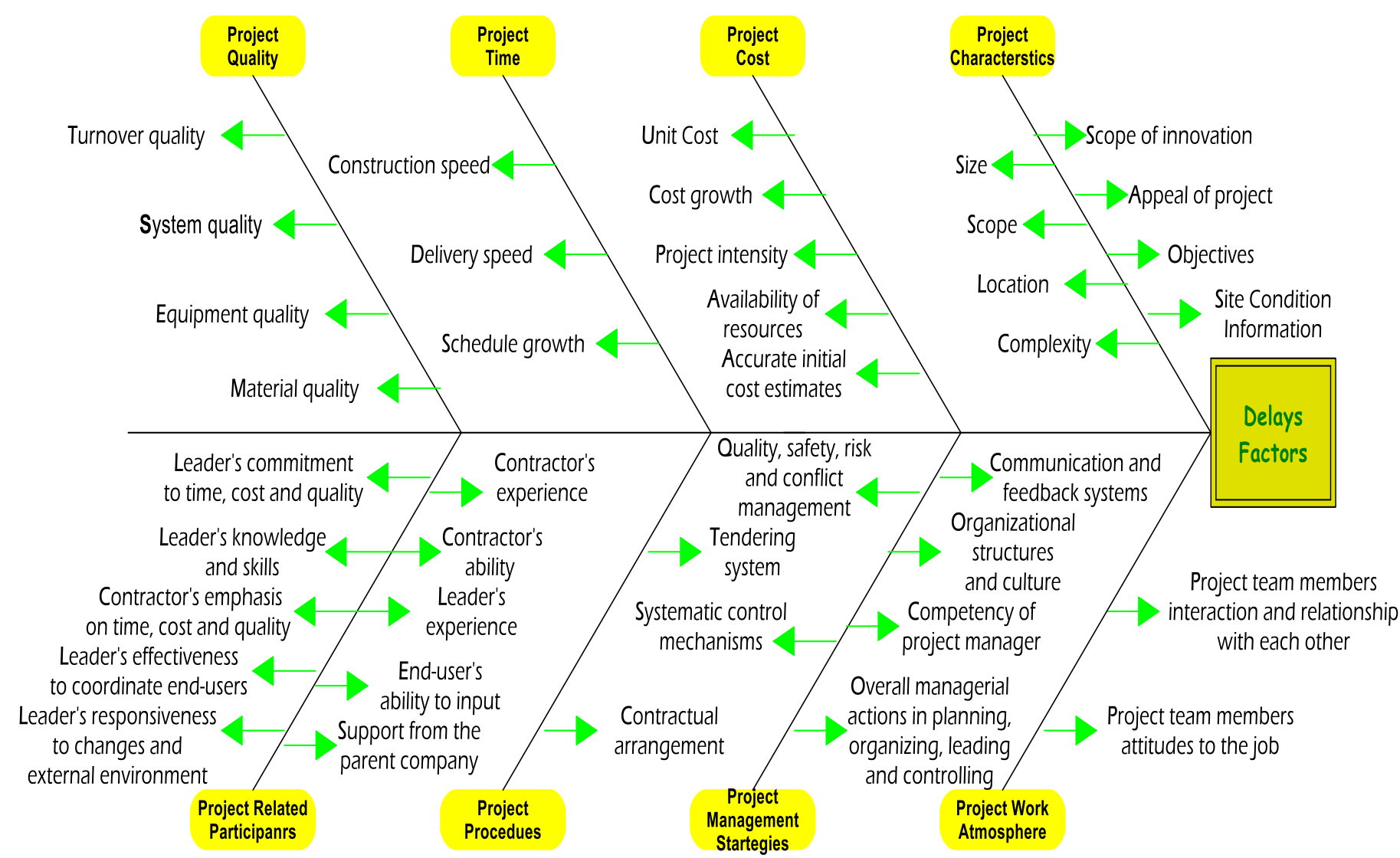

Fig.3: Factors affecting delay in the project using Ishikawa diagram 


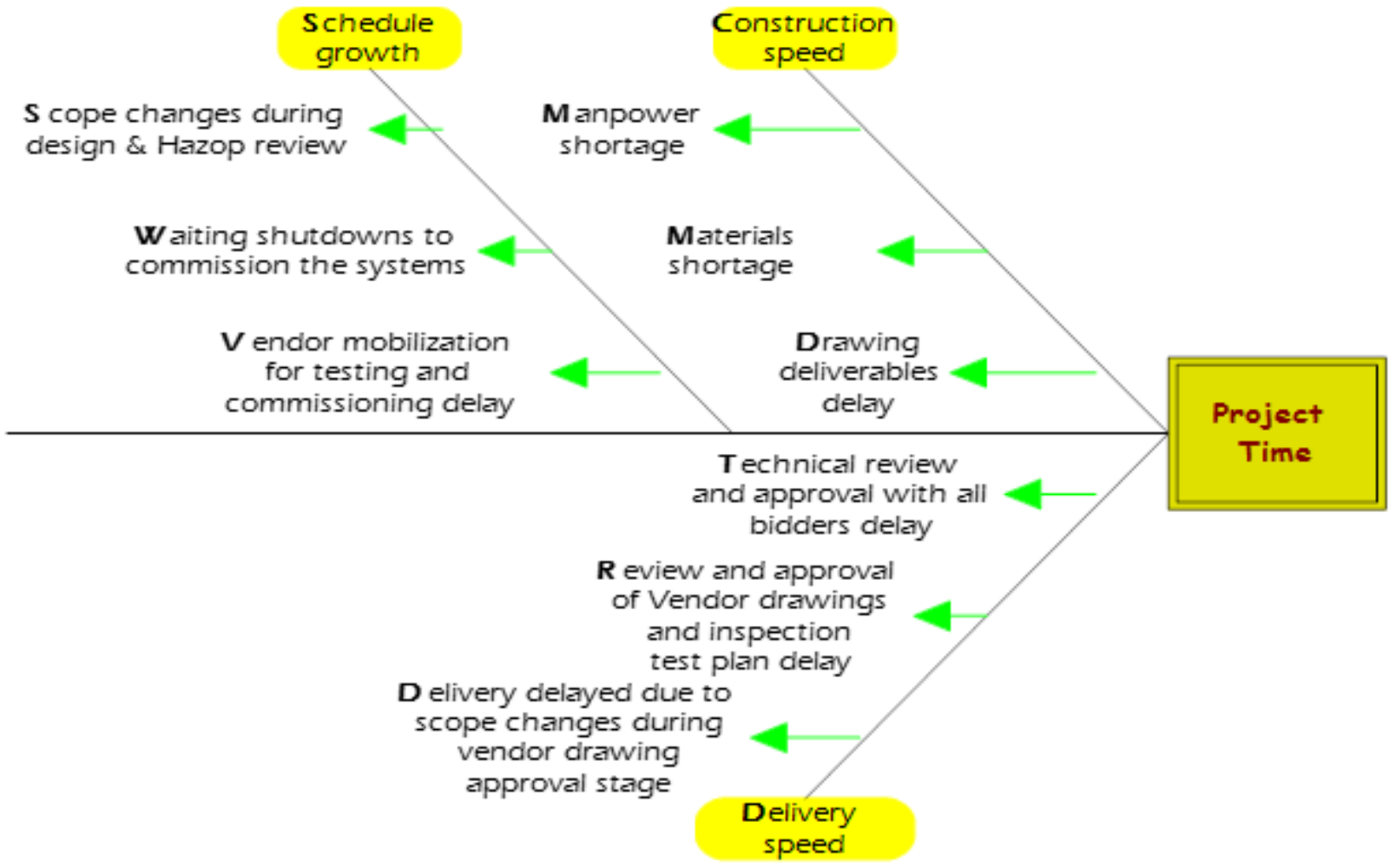

Fig.4: The root causes leading to delay due to Project time

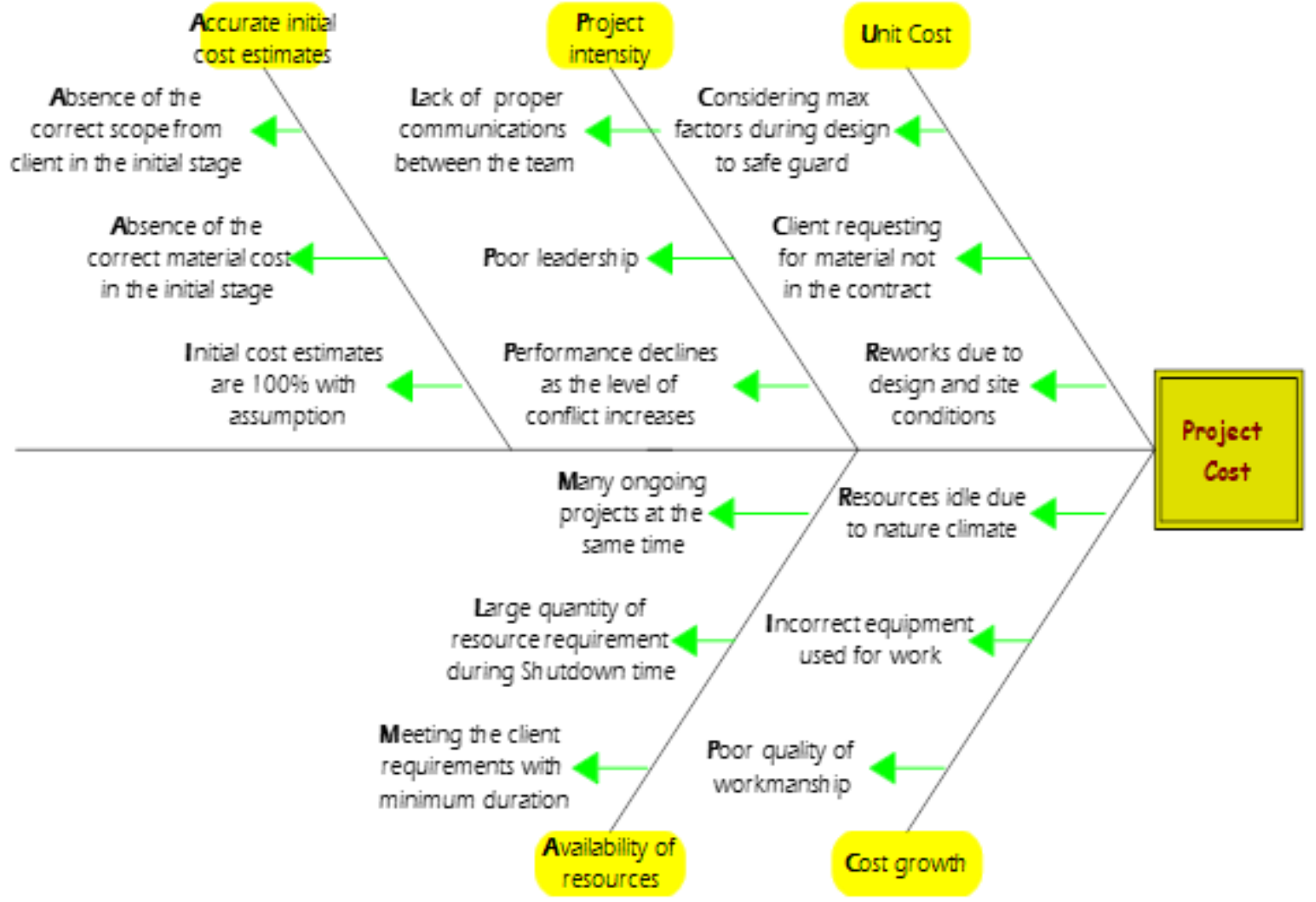

Fig.5: The root causes leading to delay due to Project cost 


\section{CONCLUSION}

The project mainly focused to identify various root causes of delay for a running EPC project by using Ishikawa diagram further a detailed questionnaire survey has been conducted to identify the critical delay factors and a Pareto chart has been prepared to illustrate the vital delay factors. For the vital delay factors, again root cause study has been conducted by using Ishikawa diagram and finally an acceleration plan has been prepared by using schedule compression techniques.

Main results obtained are:

- Through the comparison of baseline and revised schedules, the delay in each activity and total project duration was calculated.

- All the factors affecting delay in the project were represented using Ishikawa diagram.

- The analysis of questionnaire using RII method resulted in factors as critical and near critical ranges. Project cost and project time were the critical factors causing delay in the project.

- Pareto chart was used to arrange the results from the most critical to least critical factors to help identify the causes leading to delay in EPC projects.

- Root causes leading to project cost and project time affecting delay in the project were represented using Ishikawa diagram.

- Acceleration plan has been prepared by considering the results of the project.

- The study identified the importance of analyzing the root causes before taking any particular preventive measures.

\section{REFERENCES}

[1] Aibinu , Jagboro , 2002. The effects of construction delays on project delivery in Nigerian construction industry, International Journal of Project Management, 20 , pp 593-599

[2] Arditi , Pattanakitchamroon, 2006. Selecting a delay analysis method in resolving construction claims, International Journal of Project Management , 24 , pp $145-155$

[3] Abdul-Rahman, Wang, Jackson, 2011. CTM4 model using Ishikawa diagram for quality management in design-and-build projects, Scientific Research and Essays , 25 , pp 5442-5456

[4] Yang, Kao, 2009. Review of Delay Analysis Methods: A Process-Based Comparison, The Open Construction and Building Technology Journal, 3, pp 81-89
[5] Mohammed, Isah, 2012. Causes of Delay in Nigeria Construction Industry, Interdisciplinary Journal of Contemporary Research in Business, 4(2), pp 785789

[6] Gunduz, M, Nielsen, Y, and Ozdemir,M. 2013. Quantification of delay factors Using the Relative Impotance Index Method for Construction Projects in Turkey, Journal of Management Engineering, 29(2), pp 133-139

[7] Schumacher L, 2011. After-the-Fact Delay Analysis: Judging the methods, One Practitioner's View, Journal of Legislation Affairs Dispute Resolution Engineering Construction, 3(1), pp 1-9

[8] Yang J. and Wei P., 2010. Causes of Delay in Planning and Design Phases of Construction Projects, Journal of Architectural Engineering, 16(2), pp 80- 83

[9] Kraeim Z. and Diekmann,J., 1987. Concurrent delays in Construction Projects, Journal of Construction Engineering Management, 113(4), pp $591-602$

[10] Alwi, Hampson, 2003. Identifying the Important Causes of Delays in Building Construction Projects, Journal of Structural Engineering and Construction, 4(2), pp $1-6$

[11] Hegazy, 2012. Delay Analysis Methodology in UAE Construction Projects: Delay Claims, Literature Review, PM World Journal, 1(2), pp $1-21$

[12] Ramanathan, $\mathrm{C}$ et all 2012. Construction in Delays Causing Risks on Time and Cost- A Critical Review, Australasian Journal of Construction Economics and Building , 12(1), pp $37-57$

[13] Gwiazda, 2006. Quality tools in a process of technical project management, Journal of Achievements in Materials and Manufacturing Engineering, 18(1-2), pp $439-442$

[14] Akojbe, Feng, Zhou 2012. Importance and Ranking Evaluation of Delay Factors for Development Construction Projects in Benin, Journal of Civil Engineering, 17(6), pp $1213-1222$

[15]Lewis, P., 2007. Fundamentals of Project Management. 3rd edition. American Management Association.

[16] Heldman, K., 2003. Project Management Jump Start. 1 st edition. Sybex Inc.

[17] Maylor, H., 2003. Project Management. 3rd edition. Pearson Education Ltd. 